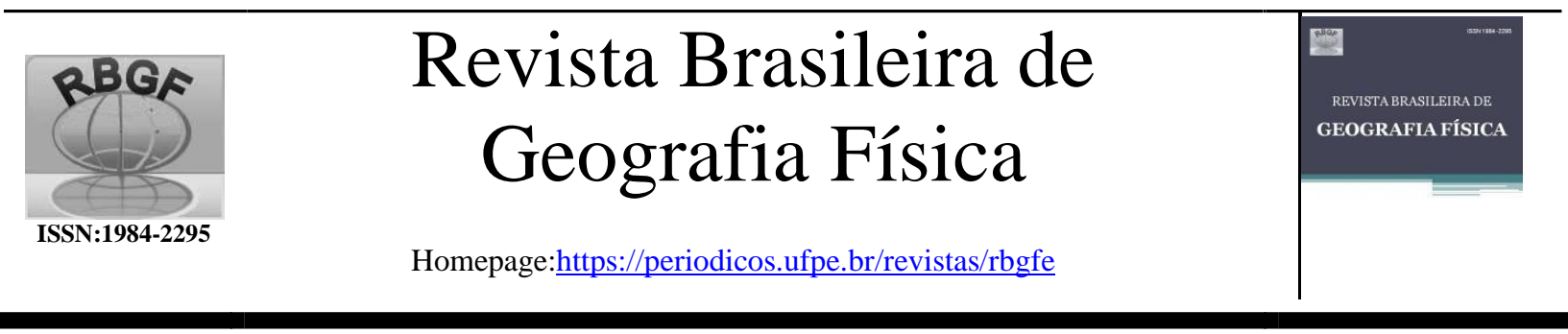

\title{
Dinâmica do uso e cobertura da terra em uma bacia hidrográfica transfonteiriça Brasil-Uruguai entre 1985 e 2017
}

\begin{tabular}{|c|c|c|}
\hline fer, & Unipampa. & correspondente \\
\hline.$e d t$ & Roger & Roldan \\
\hline
\end{tabular}
(alexandro.schafer@unipampa.edu.br); johnrroldan@gmail.com

Artigo recebido em 01/06/2020 e aceito em 27/07/2021

\section{R E S U M O}

O objetivo deste estudo foi investigar a dinâmica do uso e cobertura da terra na bacia hidrográfica do Arroio São Luiz, Brasil-Uruguai, entre 1985 e 2017, utilizando-se técnicas de sensoriamento remoto e de sistemas de informações geográficas. A realização do estudo compreendeu a delimitação da bacia hidrográfica e de sua rede de drenagem, o mapeamento do uso e cobertura da terra, o cálculo de métricas da paisagem e a determinação de transições e persistências. Detectaram-se alterações contundentes nos padrões de uso e cobertura da terra na bacia hidrográfica, tanto em território brasileiro quanto uruguaio, ocasionadas por mudanças nas atividades econômicas relacionadas ao setor agropecuário. Embora as alterações tenham ocorrido de maneira similar nas duas partes da bacia quando se considera apenas os cenários inicial (1985) e final (2017) - redução nas áreas campestres e florestais e aumento nas áreas agrícolas e nos corpos d'água constatou-se que elas ocorreram em períodos e intensidades diferentes em territórios brasileiro e uruguaio. A conversão dos campos em áreas agrícolas foi mais intensa em território uruguaio, enquanto em território brasileiro a fragmentação dos campos ocorreu com maior intensidade. As áreas florestais reduziram com intensidade semelhante nos dois países, acompanhada pela redução da fragmentação. As áreas ocupadas por corpos d'água aumentaram ao longo de todo o período de estudo, com maior intensidade em território uruguaio entre 1985 e 1996 e em território brasileiro entre 2003 e 2017.

Palavras-chave: Uso e cobertura da terra, Geoprocessamento, Arroio São Luiz.

\section{Dynamics of land use and land cover in a Brazil-Uruguay transboundary watershed between 1985 and 2017}

\begin{abstract}
This study aims to investigate the dynamics of land use and land cover (LULC) in the São Luiz river watershed, Brazil-Uruguay, between 1985 and 2017, using remote sensing and geographic information systems techniques. The study included the delimitation of the watershed and its drainage network, mapping of LULC, the calculation of landscape metrics and the determination of transitions and persistence. Severe changes in LULC patterns were detected in both the Brazilian and Uruguayan territories, caused by changes in economic activities related to the agricultural and livestock sector. Although the changes occurred similarly in both parts of the watershed based on he initial (1985) and final (2017) scenarios - reduction in the grassland and forest areas and increase in the agricultural areas and water bodies - were found that they occurred at different periods and intensities in brazilian and uruguayan territories. The conversion of grassland into agricultural areas was more intense in uruguayan territory, while inbBrazilian territory the fragmentation of the grassland occurred with greater intensity. Forest areas have reduced with similar intensity in both countries, accompanied by reduction in the fragmentation. The areas occupied by water bodies increased throughout the study period, with greater intensity in uruguayan territory between 1985 and 1996 and in brazilian territory between 2003 and 2017.
\end{abstract}

Schafer, A. G., Aleixo, J. R.R. 


\section{Introdução}

Os rios têm importância histórica e cultural na formação do Brasil. Foram caminhos naturais para a penetração no território, integração nacional e facilitaram a demarcação natural do espaço geográfico que hoje define o país (Brasil, 2013). Como muitos desses rios são compartilhados com outros países, a questão as águas transfronteiriças é um tema atual e relevante.

Segundo Brasil (2013) os rios podem ser classificados como rios contíguos ou rios contínuos, de acordo com a maneira que se dá o compartilhamento das águas com outros países. Os rios contíguos (fronteiriços) são caracterizados por possuírem margens em países distintos e que formam, portanto, fronteiras terrestres. Já os rios contínuos (transfronteiriços) atravessam o limite de dois estados ou nações. As bacias hidrográficas que perpassam as fronteiras de dois ou mais países são classificadas como internacionais e/ou transfronteiriças, dado que seus sistemas geohidrológicos ocupam territórios de dois ou mais países, e suas águas são utilizadas para diversas finalidades e por múltiplos atores (Garcia e Ribeiro, 2016). De acordo com Soares (2002), mais de $60 \%$ do território nacional encontra-se dentro de áreas de drenagem de bacias transfronteiriças.

A gestão de recursos hídricos fronteiriços e transfronteiriços são estratégicas para o Brasil, uma vez que fenômenos hidrológicos que envolvem os regimes hídricos, as secas, as inundações, as condições ambientais do entorno dos cursos d'água e as consequências de seus usos, ocorridos de um lado ou de outro das fronteiras políticas, afetam a totalidade da bacia (Brasil, 2013). Conforme argumentam Das et al. (2018), os fluxos químico, de água e de energia do sistema terrestre estão integrados através do ciclo hidrológico e qualquer força externa, em particular no que se refere a atividades antropogênicas, pode ter um impacto significante nesses fluxos.

Levando em consideração que o valor
estratégico de bacias hidrográficas
transfronteiriças pode instigar disputas e/ou
preocupações quanto à segurança regional (ou,
por outro lado, a cooperação entre nações), é
importante que sejam realizados estudos que

tenham o potencial de contribuir para o gerenciamento dessas bacias. Nesse sentido, a articulação da gestão dos recursos hídricos com a gestão territorial tem grande relevância. No contexto da gestão territorial, a quantificação e o monitoramento das mudanças no uso e cobertura da terra são essenciais (Jimenez et al., 2018), já que refletem o inter-relacionamento entre atividades humanas/sociais/econômicas e os processos ecológicos naturais (Chen et al., 2018), sendo um dos indicadores utilizados para determinar o impacto de atividades antropogênicas nos ecossistemas (Luo et al., 2018).

No caso do Brasil e do Uruguai, existem três bacias hidrográficas transfronteiriças: A bacia da Lagoa Mirim (na região hidrográfica do Atlântico Sul), a bacia do Rio Negro e a bacia do Rio Quaraí (ambas na região hidrográfica do Uruguai). Essas três bacias hidrográficas são consideradas áreas especiais para gestão, de acordo com ANA (2015), pois possuem trechos críticos de rios federais segundo o balanço hídrico quali-quantitativo. Atualmente existem acordos de cooperação entre o Brasil e o Uruguai para o aproveitamento dos recursos naturais e o desenvolvimento das bacias hidrográficas da Lagoa Mirim (Brasil, 1977) e do Rio Quaraí (Brasil, 1991).

A bacia hidrográfica do Rio Negro é a única que ainda não possui acordo de cooperação entre o Brasil e o Uruguai. Essa bacia apresenta balanço hídrico quantitativo crítico, associado a alta demanda para irrigação (ANA, 2015). Segundo Ravanello e Pante (2013), não é possível atender a todos os usuários irrigantes na parte brasileira da bacia hidrográfica no período de safra do arroz (de outubro a março). O déficit hídrico é agravado significantemente nos períodos de estiagem, que são recorrentes na região. Desta maneira, embora não existam conflitos quanto ao uso da água entre usuários das partes brasileira e uruguaia da bacia hidrográfica atualmente, é possível que surjam conflitos em um futuro próximo como consequência do aumento da atividade agrícola, bem como das mudanças climáticas previstas para a região (por exemplo, Cabré et al. (2016) preveem aumento da precipitação no verão e no outono e redução da precipitação no inverno e primavera). 
$\mathrm{Na}$ bacia hidrográfica do Rio Negro existem quatro cursos d'água compartilhados com o Uruguai, sendo três deles contínuos ou transfronteiriços: Arroio Carpintaria, Arroio São Miguel e Rio Negro. O único curso d'água contiguo (fronteiriço), é o Arroio São Luiz, que delineia aproximadamente $30 \mathrm{~km}$ da fronteira entre o Brasil e o Uruguai. Devido ao recente avanço da agricultura, têm-se testemunhado considerável alteração nos padrões de uso e cobertura da terra da bacia hidrográfica do Arroio São Luiz, que tem o potencial de alterar a sua hidrologia e fomentar conflitos entre os usuários da água dos dois países em sua área de abrangência. Nesse contexto, o presente estudo teve como objetivo mapear e quantificar a dinâmica do uso e ocupação da terra na área de abrangência da bacia hidrográfica do Arroio São Luiz, em um período de 32 anos, entre 1985 e 2017. Para tanto, utilizou-se técnicas de Sensoriamento Remoto, de Sistemas de Informações Geográficas e de Análise da paisagem, com base em uma série histórica de imagens do satélite Landsat TM e OLI (imageadas em 1985, 1996, 2003 e 2017).

\section{Área de estudo}

A bacia hidrográfica do Arroio São Luiz (Figura 1) faz parte da bacia hidrográfica do Rio Negro (Brasil e Uruguai) e está localizada entre as coordenadas $31^{\circ} 18^{\prime} 07^{\prime \prime}$ e $31^{\circ} 31^{\prime} 52^{\prime \prime}$ sul e $54^{\circ}$ $18^{\prime} 54^{\prime \prime}$ e $54^{\circ} 20^{\prime} 31^{\prime \prime}$ oeste. A bacia abrange parte dos municípios de Bagé-RS e Dom Pedrito, do lado brasileiro, e parte do departamento de Rivera, no Uruguai. O Arroio São Luiz tem um comprimento de aproximadamente $45 \mathrm{~km}$ e sua área de drenagem é de aproximadamente 49.263,60ha, sendo 24.877,00ha em território brasileiro e $24.386,60 \mathrm{ha}$ em território uruguaio. De acordo com dados do Cadastro Ambiental rural (CAR), existem 85 propriedades rurais na área de abrangência da bacia do Arroio São Luiz em território brasileiro, com áreas entre $1,79 \mathrm{ha} \mathrm{e}$ 4.104,91ha. Já do lado uruguaio, existem 74 propriedades rurais, com área entre 2,00ha e 3.023,00ha, de acordo com os dados da Dirección Nacional de Catastro (DNC, 2019).



Figura 1: Localização da bacia hidrográfica do Arroio São Luiz. Organização: Os autores, 2019. 
Segundo a classificação de Köeppen, a região onde a bacia hidrográfica do Arroio São Luiz está inserida apresenta clima subtropical ou virginiano $(\mathrm{Cfa})$, pertencente à área morfoclimática denominada Escudo SulRiograndense-Uruguaio. As temperaturas médias máximas giram em torno de $24,1^{\circ} \mathrm{C}$ e as médias mínimas em torno de $13,1^{\circ} \mathrm{C}$. A precipitação média anual (registrada na estação de Bagé) fica em torno de $1.423 \mathrm{~mm}$. Os solos do tipo Brunizem e Planossolo abrangem a maior parte da bacia hidrográfica, que tem altitudes entre $119 \mathrm{~m}$ e $244 \mathrm{~m}$.

\section{Material e método}

A realização do estudo compreendeu as seguintes etapas: a) Delimitação da bacia hidrográfica e de sua rede de drenagem; b) Mapeamento do uso e cobertura da terra nos cenários de 1985, 1996, 2003 e 2017; c) Cálculo de métricas da paisagem e; d) Determinação de transições e persistências nas classes de uso e cobertura da terra.

A bacia hidrográfica do Rio Negro foi delimitada através da utilização de dados de imagens obtidas por interferometria de radar da missão TanDEM-X (Wessel et al., 2018; Rizzoli et al., 2017), com resolução espacial de noventa metros, utilizando a extensão Archydro (Maidment, 2002) do software ArcGIS, em nove etapas: a) preenchimento dos sumidouros; b) Direção de fluxo; c) Acumulação de fluxo; d) Definição da rede de drenagem; e) Segmentação da rede de drenagem; f) Geração da grade de micro-bacias; g) Geração das linhas de drenagem; h) Junção das linhas de drenagem e micro-bacias e; i) Delimitação da bacia hidrográfica.

A segunda etapa do estudo consistiu no mapeamento do uso e cobertura da terra, realizado a partir da classificação supervisionada de quatro imagens da série de satélites Landsat (sensor TM para as imagens de 1985, 1996 e 2003 e sensor OLI para a imagem de 2017), usando o método da Máxima Verossimilhança (MaxVer). Se utilizou a base cartográfica vetorial contínua do Rio Grande do Sul, na escala 1:50.000 (Hasenack e Weber, 2010) para a correção geométrica das imagens. A normalização radiométrica foi realizadas na etapa de pré-processamento. Após a classificação supervisionada, foi realizada pós-classificação com o objetivo de minimizar os erros identificados durante as saídas de campo e em consultas a imagens de alta resolução disponíveis no Google Earth. A validação do mapeamento do uso e da cobertura da terra foi realizada através da análise qualitativa e quantitativa dos dados gerados após essa etapa. Na análise qualitativa, foi realizada a comparação entre o mapa temático oriundo da classificação e as verdades terrestres, juntamente com o conhecimento adquirido nas saídas de campo. Para a imagem de 2003, utilizaram-se imagens de alta resolução disponíveis no Google Earth. $\mathrm{Na}$ análise quantitativa, foi considerado o coeficiente Kappa, índice que quantifica a exatidão do mapeamento a partir de uma escala proposta por Landis e Koch (1977). Os coeficientes Kappa obtidos após a etapa de pós-classificação foram de 0,873 para $1985,0,896$ para $1996,0,871$ para 2003 e 0,952 para 2017.

A terceira etapa do estudo compreendeu a determinação das seguintes métricas da paisagem, calculadas a partir dos arquivos matriciais de uso e cobertura da terra (gerados na etapa anterior), utilizando o programa computacional Fragstats 2.0 (Mcgarigal et al., 2012): a) percentagem da paisagem correspondente a cada classe de uso e cobertura da terra; b) número de fragmentos e; c) área média dos fragmentos.

A última etapa do estudo consistiu na determinação das transições e persistências que ocorreram em cada classe de uso e cobertura da terra, realizada a partir de: (a) reclassificação: a imagem resultante do processo de classificação foi reclassificada para uma imagem binária e; (b) cruzamento booleano: realizado entre as imagens binárias de dois anos distintos, cujo resultado poderia resultar em quatro situações: 1) Surgimento: locais ocupados por uma classe de uso e cobertura da terra na data inicial que foram ocupados pela classe em análise na data final; 2) Permanência: locais ocupados pela classe em análise nas duas datas; 3) Ausência: locais não ocupados pela classe em análise tanto na data inicial quanto na data final; 4) Extinção: locais ocupados pela classe de uso e cobertura da terra em análise na data inicial que passaram a ser ocupados por outra classe na data final.

\section{Resultados}

A distribuição espacial das classes de uso e cobertura da terra na bacia hidrográfica do Arroio São Luiz referente aos cenários de 1985, 1996, 2003 e 2017 é apresentada na figura 2. Nos 
gráficos da figura 3 apresenta-se a quantificação do uso e cobertura da terra nas cinco classes mapeadas ao longo do período em estudo. $\mathrm{Na}$ figura 3a tem-se a quantificação para toda a área da bacia hidrográfica, enquanto nas figuras $3 \mathrm{~b}$ e $3 c$ apresenta-se a quantificação para as partes da bacia em territórios brasileiro e uruguaio, respectivamente. 
Revista Brasileira de Geografia Física v.014, n.04 (2021) 2304-2321.

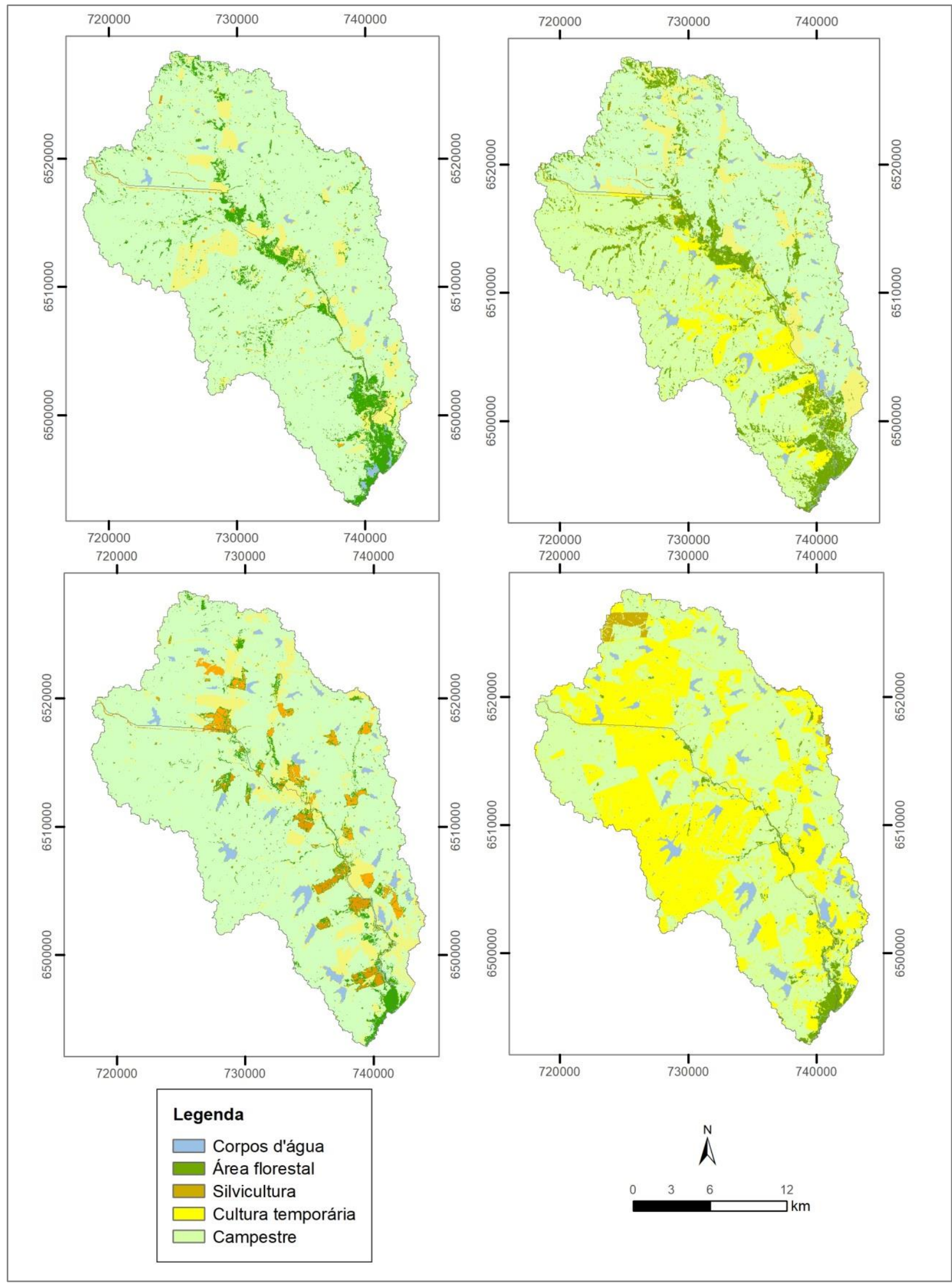

Figura 2: Padrão espacial do uso e cobertura da terra na bacia hidrográfica do Arroio São Luiz nos cenários de 1985, 1996, 2003 e 2017. Fonte: Os autores, 2019. 

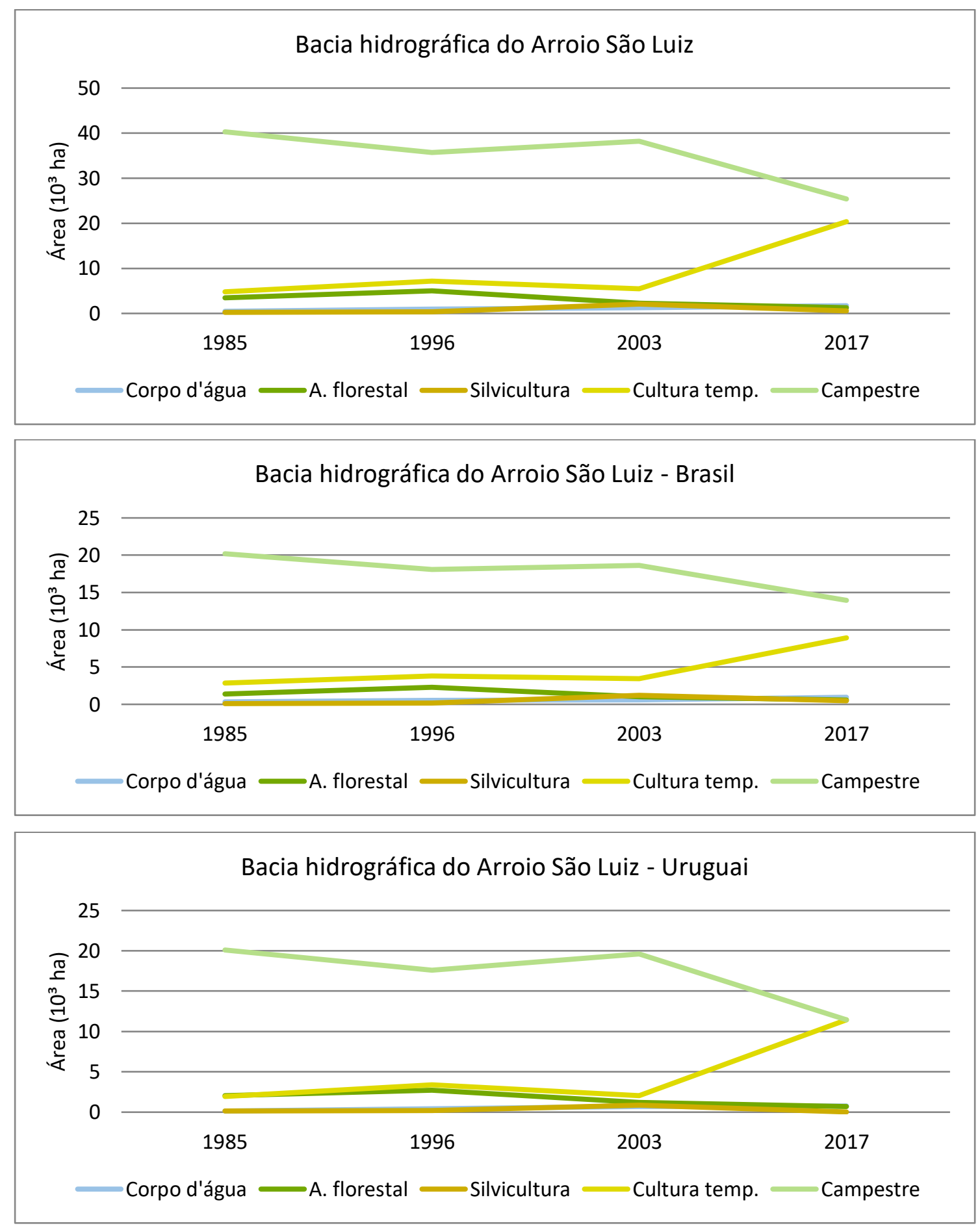

Figura 3: Quantificação do uso e cobertura da terra na bacia hidrográfica do Arroio São Luiz em 1985, 1996, 2003 e 2017. Fonte: Os autores, 2019.

Nas Figuras 2 e 3 é possível verificar que as classes de uso e cobertura da terra predominantes na bacia hidrográfica ao longo do período em estudo foram a "Campestre", a "Área florestal" e a "Cultura temporária". No cenário de 1985, a classe "Campestre" ocupava aproximadamente 40.300ha, sendo 20.1295ha no Brasil e 20.105ha no Uruguai. As culturas temporárias abrangiam 4.794ha, 2.852ha no Brasil

Schafer, A. G., Aleixo, J. R.R. e 1.942ha no Uruguai. As áreas florestais compreendiam 3.461ha, 1.403ha do lado brasileiro e 2.058ha do lado uruguaio. Os corpos d'água, compostos basicamente por barragens e cursos d'água, abrangiam 333ha no Brasil e 143ha no Uruguai, totalizando 476ha. Por fim, a silvicultura ocupava 233ha, 95ha no Brasil e 138ha no Uruguai. 
No cenário referente a 1996, a classe "Campestre" passou a ocupar 35.718ha, sendo 18.114ha no Brasil e 17.603ha no Uruguai. As culturas temporárias abrangiam 7.214ha, 3.808ha no Brasil e 3.406ha no Uruguai. As áreas florestais compreendiam 5.008ha, 2.287ha do lado brasileiro e 2.721 ha do lado uruguaio. Os corpos d'água abrangiam 511ha no Brasil e 446ha no Uruguai, totalizando 957ha. Por fim, a silvicultura ocupava 677ha, 157ha no Brasil e 210ha no Uruguai.

No cenário referente a 2003, a classe "Campestre" passou a ocupar 38.204ha, sendo 18.607ha no Brasil e 19.597ha no Uruguai. As culturas temporárias abrangiam 5.464ha, 3.411ha no Brasil e 2.052ha no Uruguai. As áreas florestais compreendiam 2.235ha, 1.040ha do lado brasileiro e 1.195 ha do lado uruguaio. Os corpos d'água abrangiam 610ha no Brasil e 677ha no Uruguai, totalizando 1.287ha, enquanto a silvicultura ocupava 2.074ha, 1.209ha no Brasil e 865ha no Uruguai.

No cenário referente a 2017, a classe "Campestre" passou a ocupar 25.399ha, sendo 13.947ha no Brasil e 11.452ha no Uruguai. As culturas temporárias abrangiam 20.365ha, 8.917ha no Brasil e 11.448ha no Uruguai. As áreas florestais compreendiam 1.274ha, 577ha do lado brasileiro e 697ha do lado uruguaio. Os corpos d'água abrangiam 949ha no Brasil e 766ha no Uruguai, totalizando 1.716 ha. A silvicultura ocupava 510ha, 486ha no Brasil e 24ha no Uruguai.

Em 1985 verifica-se similaridade entre a estrutura da paisagem nas partes brasileira e Uruguaia da bacia hidrográfica. Havia predomínio dos campos, enquanto as áreas florestais e áreas destinadas à agricultura ocupavam áreas menores. Em linhas gerais, a dinâmica do uso e cobertura da terra foi semelhante nas áreas que abrangem os dois países ao longo do período em estudo: as áreas campestres reduziram entre 1985 e 1996, aumentaram entre 1996 e 2003 e voltaram a reduzir entre 2003 e 2017. Já as classes "Área florestal" e "Cultura temporária" apresentaram aumento entre 1985 e 1996 e redução entre 1996 e 2003. Entre 2003 e 2017 essas classes apresentaram comportamentos diferentes: enquanto as áreas florestais reduziram, as áreas destinadas a culturas temporárias aumentaram consideravelmente.

Embora as mudanças no uso e cobertura da terra tenham apresentado tendências similares tanto na parte brasileira quanto na parte uruguaia da bacia hidrográfica, a intensidade dessas mudanças foi diferente. Nos gráficos da figura 4 apresentam-se as quantificações das mudanças (em área) no uso e cobertura da terra nos três períodos em estudo: 1985-1996, 1996-2003 e 2003-2017.

Nas figuras $4 a$ e $4 b$, é possível verificar que a intensidade das mudanças ao longo do período em estudo foi maior em território uruguaio para todas as classes de uso e cobertura da terra e em todos os períodos analisados, com exceção do aumento da silvicultura no período 1996-2003 e da área ocupada pelos corpos d'água no período 20032017. Destaca-se, no último período, o expressivo aumento das áreas destinadas às culturas temporárias, que foi acompanhado por redução substancial das áreas campestres.

Para compreender individualmente a dinâmica do uso e cobertura da terra de cada classe, apresenta-se a seguir uma análise das transições, das persistências e da fragmentação ao longo do período em estudo. Na figura 5 apresentam-se as transições e persistências, enquanto no gráfico da figura 6 apresenta-se a quantificação das mudanças no número e na área média dos fragmentos que ocorreram na classe "Campestre". 
Revista Brasileira de Geografia Física v.014, n.04 (2021) 2304-2321.

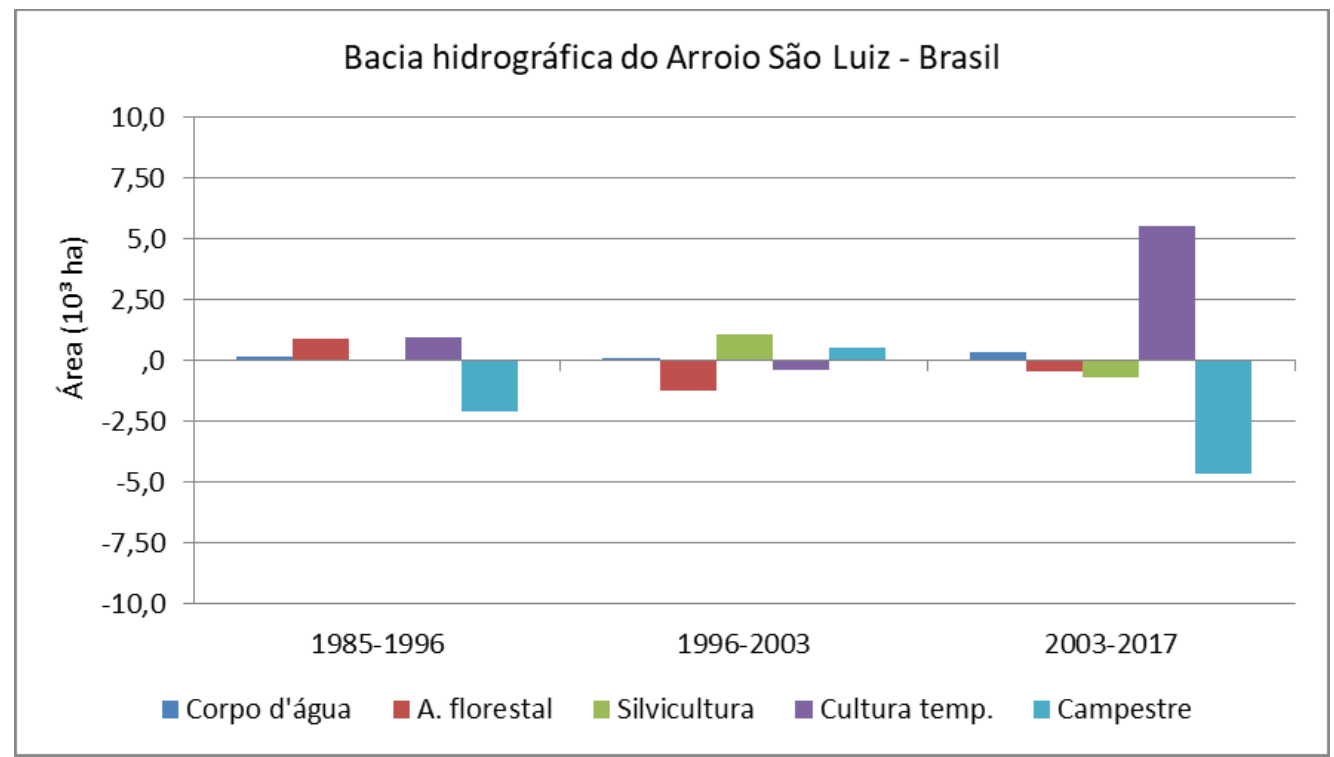

Figura 4a: Quantificação das alterações do uso e cobertura da terra nos períodos em estudo. Fonte: Os autores, 2019.



Figura 4b: Quantificação das alterações do uso e cobertura da terra nos períodos em estudo. Fonte: Os autores, 2019. 
Revista Brasileira de Geografia Física v.014, n.04 (2021) 2304-2321.

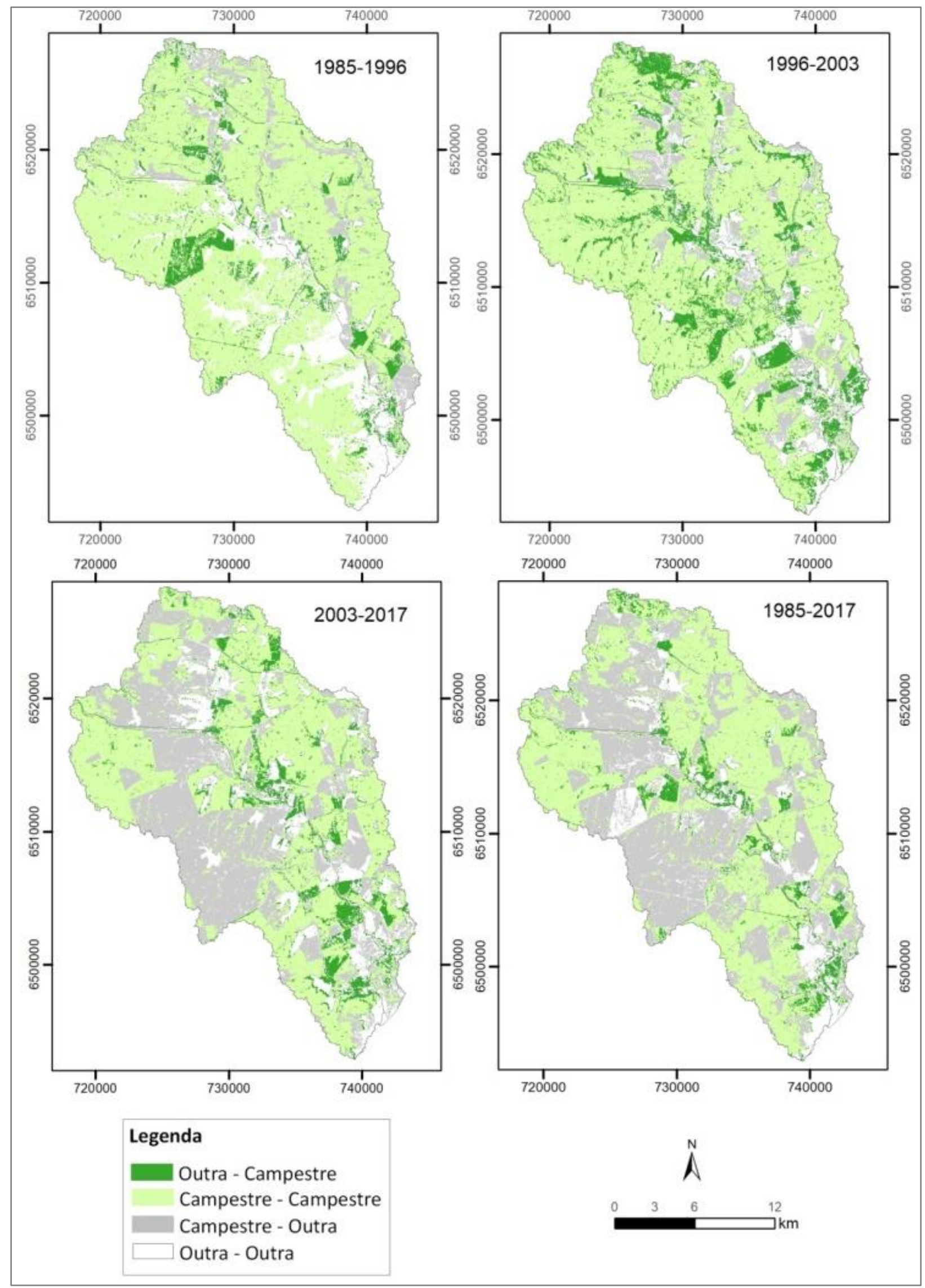

Figura 5: Distribuição espacial das transições e persistências da classe "campestre" no período em estudo. Fonte: Os autores, 2019. 


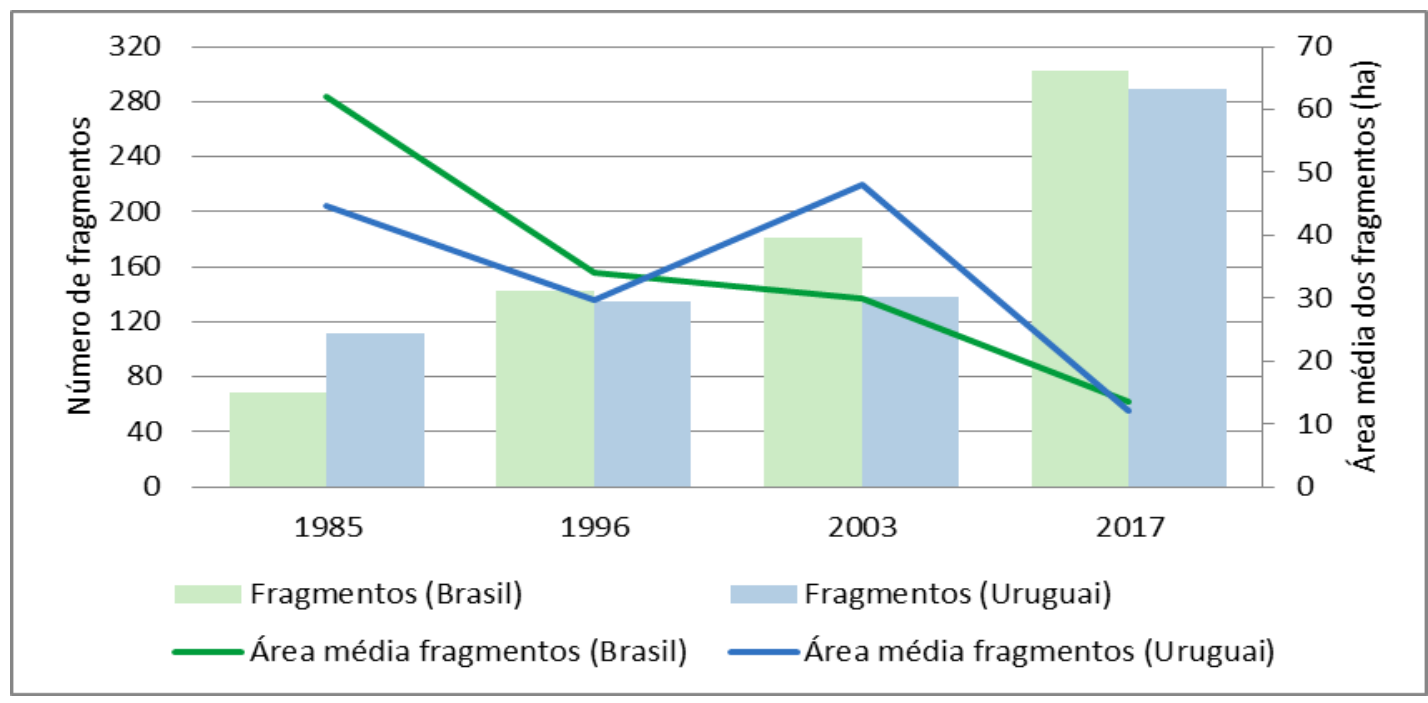

Figura 6: Número e área média de fragmentos na classe "Campestre" no período em estudo.

Fonte: Os autores, 2019.

As áreas campestres sofreram drástica redução ao longo do período em estudo, apresentando maior intensidade de alteração em território uruguaio. Os campos, que ocupavam $81,20 \%$ e $82,44 \%$ da área total das partes brasileira e uruguaia da bacia hidrográfica, respectivamente, passaram a representar apenas $56,06 \%$ e 46,96\%, em 2017. Na figura 6, é possível verificar que houve expressivo aumento no número de fragmentos, acompanhado pela redução na sua área média, tanto na parte brasileira quanto na parte uruguaia da bacia hidrográfica.

Na comparação entre 1985 e 1996, as áreas campestres reduziram a uma taxa de 416,62ha ano $^{-1}$, sendo a 189,16ha ano ${ }^{-1} \mathrm{em}$ território brasileiro e a 227,46ha ano $^{-1}$ em território uruguaio. Houve aumento no número de fragmentos e redução na sua área média. Os campos em território brasileiro passam a apresentar mais fragmentos que em território uruguaio. Entre 1996 e 2003, registrou-se aumento das áreas campestres, a uma taxa de 355,19 ha ano $^{-1}$, com 70,33 ha ano $^{-1}$ na parte brasileira e $284,86 \mathrm{ha} \mathrm{ano}^{-1}$ na parte uruguaia. Em território brasileiro, o número de fragmentos aumentou, enquanto sua área media reduziu. Em território uruguaio, não houve alteração no número de fragmentos, enquanto sua área média aumentou consideravelmente. Entre 2003 e 2017, registrou-se redução drástica das áreas campestres, a uma taxa de 914,67 ha ano $^{-1}$, sendo a $332,87 \mathrm{ha} \mathrm{ano}^{-1}$ (que corresponde a $18,73 \%$ da parte brasileira da bacia) no Brasil e a 581,79ha ano $^{-1}$ (que corresponde a $25,99 \%$ da parte uruguaia da bacia) no Uruguai.

$\mathrm{Na}$ figura 7 apresentam-se as transições e persistências, enquanto no gráfico da figura 8 apresenta-se a quantificação das mudanças no número e na área média dos fragmentos que ocorreram nessa classe. 


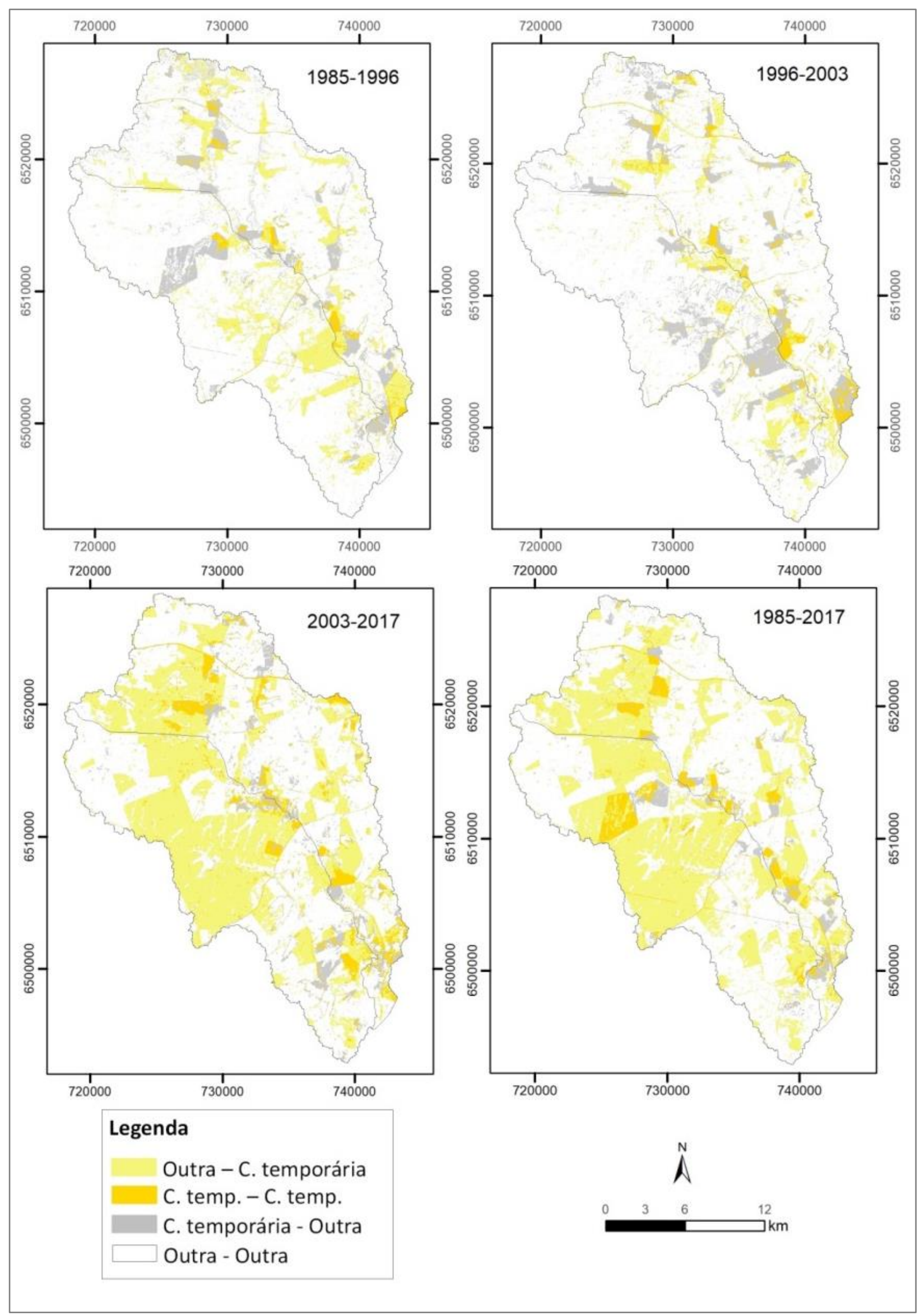

Figura 7: Distribuição espacial das transições e persistências da classe "Cultura temporária" no período em estudo. Fonte: Os autores, 2019.

Schafer, A. G., Aleixo, J. R.R. 




Figura 8: Número e área média de fragmentos da classe "Cultura temporária" na bacia do Arroio São Luiz entre 1985 e 2017.Fonte: Os autores, 2019.

Em 1985, as áreas destinadas a culturas temporárias ocupavam $11,46 \%$ e $13,97 \%$ da área das partes da bacia hidrográfica em territórios brasileiro e uruguaio, respectivamente. Já em 2017, passaram a ocupar $35,85 \%$ e $46,94 \%$. Na figura 8, é possível verificar comportamentos distintos com relação à fragmentação das culturas temporárias, nos territórios brasileiro e uruguaio. Registrou-se aumento nas áreas ocupadas pela classe "Cultura temporária" nos períodos 19851996 e 2003-2017 e redução no período 19962003. O maior aumento nas áreas destinadas a essa classe foi registrado no período 2003-2017: 5.506ha em território brasileiro e 9.395,46ha em território uruguaio. Considerando todo o período em estudo, o aumento das áreas destinadas às culturas temporárias apresentou maior intensidade de alteração em território uruguaio.

Na comparação entre 1985 e 1996 houve aumento nas áreas destinadas a culturas temporárias, a uma taxa de $219,99 \mathrm{ha} \mathrm{ano}^{-1}$, sendo a 86,95ha ano $^{-1}$ em território brasileiro e a 133,04ha ano $^{-1} \mathrm{em}$ território uruguaio. O número de fragmentos aumentou, com maior intensidade em território uruguaio, acompanhado pelo aumento em sua área média. Entre 1996 e 2003, registrou-se redução na classe "Cultura temporária", a uma taxa de 250,02 ha ano $^{-1}$, com $56,63 \mathrm{ha} \mathrm{ano}^{-1}$ na parte brasileira e $193,40 \mathrm{ha} \mathrm{ano}^{-1}$ na parte uruguaia. $O$ número de fragmentos aumentou do lado brasileiro, com pequeno aumento em sua área média. Já em território uruguaio, houve redução no número de fragmentos com redução de sua área média. Entre 2003 e 2017, registrou-se novo aumento das áreas destinadas a culturas temporárias, a uma taxa de 1064,39ha ano a $^{-1}$, sendo a 393,29 ha ano $^{-1}$ no Brasil e a $671,10 \mathrm{ha} \mathrm{ano}^{-1}$ no Uruguai. $\mathrm{O}$ número de fragmentos reduziu consideravelmente em toda a bacia hidrográfica, enquanto a área média aumento, com maior intensidade em território uruguaio.

$\mathrm{Na}$ figura 9 apresentam-se as transições e persistências e na figura 10 apresenta-se a quantificação das mudanças no número e na área média dos fragmentos que ocorreram na classe "Área florestal". 
Revista Brasileira de Geografia Física v.014, n.04 (2021) 2304-2321.



Figura 9: Distribuição espacial das transições e persistências da classe “Área florestal” no período em estudo. Fonte: Os autores, 2019.

Schafer, A. G., Aleixo, J. R.R. 


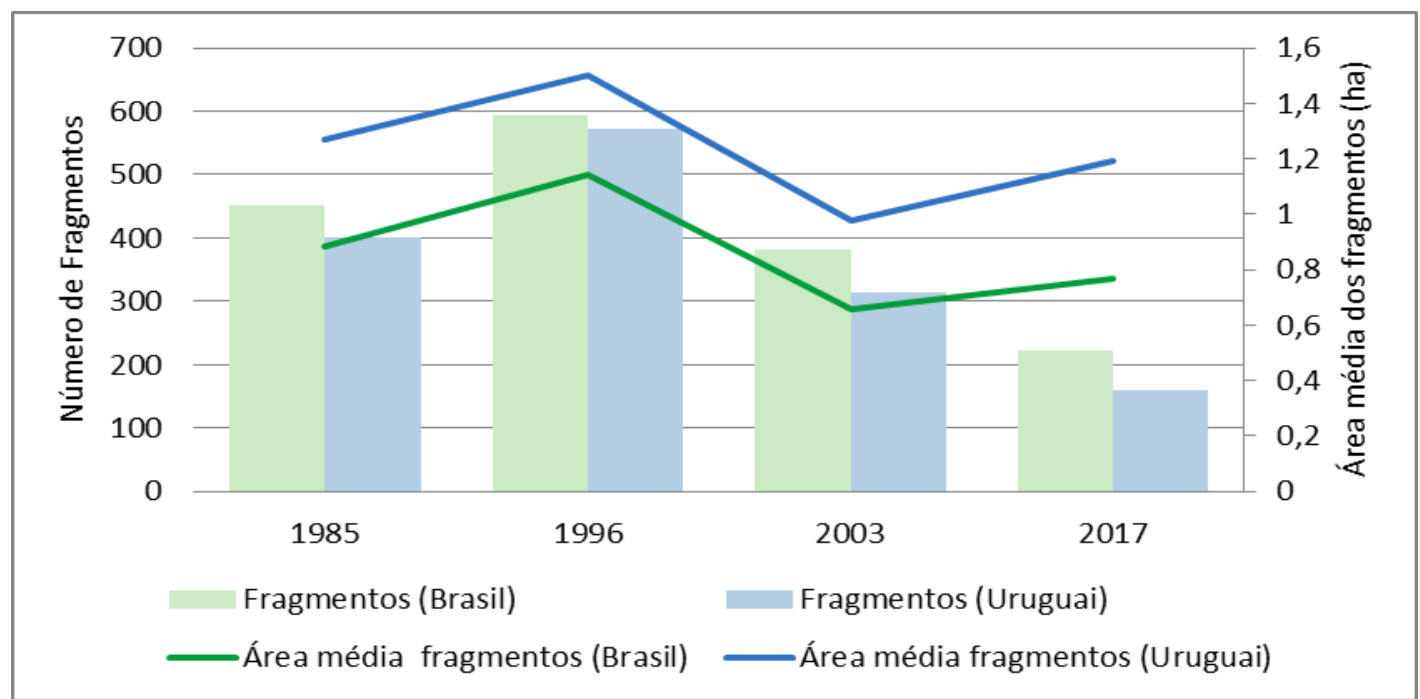

Figura 10: Número e área média de fragmentos da classe "Área florestal” no período em estudo. Fonte: Os autores, 2019.

Ao longo do período em estudo, verificou-se uma expressiva redução nas áreas florestais. Em 1985, elas ocupavam 5,64\% e $8,44 \%$ das partes brasileira e uruguaia da bacia hidrográfica, respectivamente. Em 2017, foram reduzidas a $2,32 \%$ e $2,86 \%$. Na figura 10 , é possível verificar comportamentos semelhantes com relação à fragmentação das áreas florestais nos territórios brasileiro e uruguaio. O número de fragmentos foi maior do lado brasileiro, enquanto a área média dos fragmentos foi maior do lado uruguaio, em todos os cenários analisados. Registrou-se aumento das áreas florestais no período 1985-1996 e redução nos demais períodos. As áreas florestais apresentaram maior intensidade de alteração (tanto de aumento quanto de redução) em território uruguaio. No período 1996-2003 registraram-se as maiores perdas de áreas florestais: 1247 ha em território brasileiro e 1526ha em território uruguaio.

Na comparação entre 1985 e 1996, as áreas florestais aumentaram a uma taxa de 140,65ha ano , $^{-1}$ sendo a 80,42ha ano $^{-1}$ em território brasileiro e a $60,23 \mathrm{ha} \mathrm{ano}^{-1}$ em território uruguaio. $\mathrm{O}$ número de fragmentos aumentou em toda a bacia e foi acompanhado pelo aumento em sua área média. Entre 1996 e 2003, registrou-se redução nas áreas florestais, a uma taxa de 396,09 ha $^{\text {ano }}{ }^{-1}$, com 178,16 ha ano $^{-1}$ na parte brasileira e $217,93 \mathrm{ha}$ ano $^{-1}$ na parte uruguaia. $\mathrm{O}$ número de fragmentos reduziu em toda a bacia hidrográfica e foi acompanhado pela redução em sua área média. Entre 2003 e 2017, registrou-se nova redução das áreas campestres, a uma taxa de $68,66 \mathrm{ha}^{\text {ano }^{-1}}$, sendo a $33,03 \mathrm{ha} \mathrm{ano}^{-1}$ no Brasil e a 35,63 ha ano ${ }^{-1}$ no Uruguai. $O$ número de fragmentos apresentou nova redução em toda a área da bacia hidrográfica, com aumento de sua área média.

$\mathrm{Na}$ figura 11 apresentam-se as transições e persistências, enquanto no gráfico da figura 12 apresenta-se a quantificação das mudanças no número e na área média dos fragmentos que ocorreram na classe "Corpo d'água". 
Revista Brasileira de Geografia Física v.014, n.04 (2021) 2304-2321.

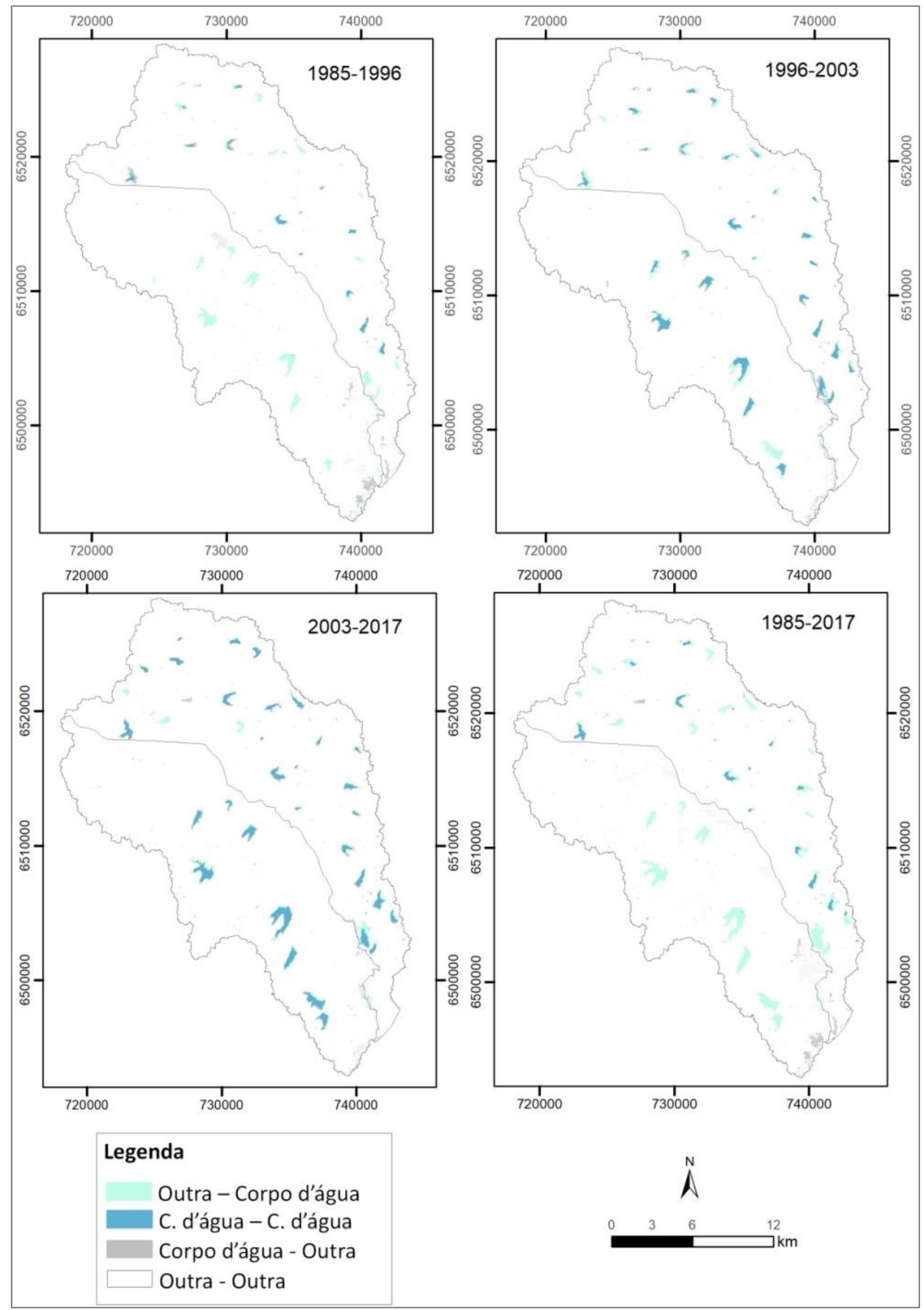

Figura 11: Distribuição espacial das transições e persistências da classe "Corpo d'água" no período em estudo. Fonte: Os autores, 2019.

Schafer, A. G., Aleixo, J. R.R. 


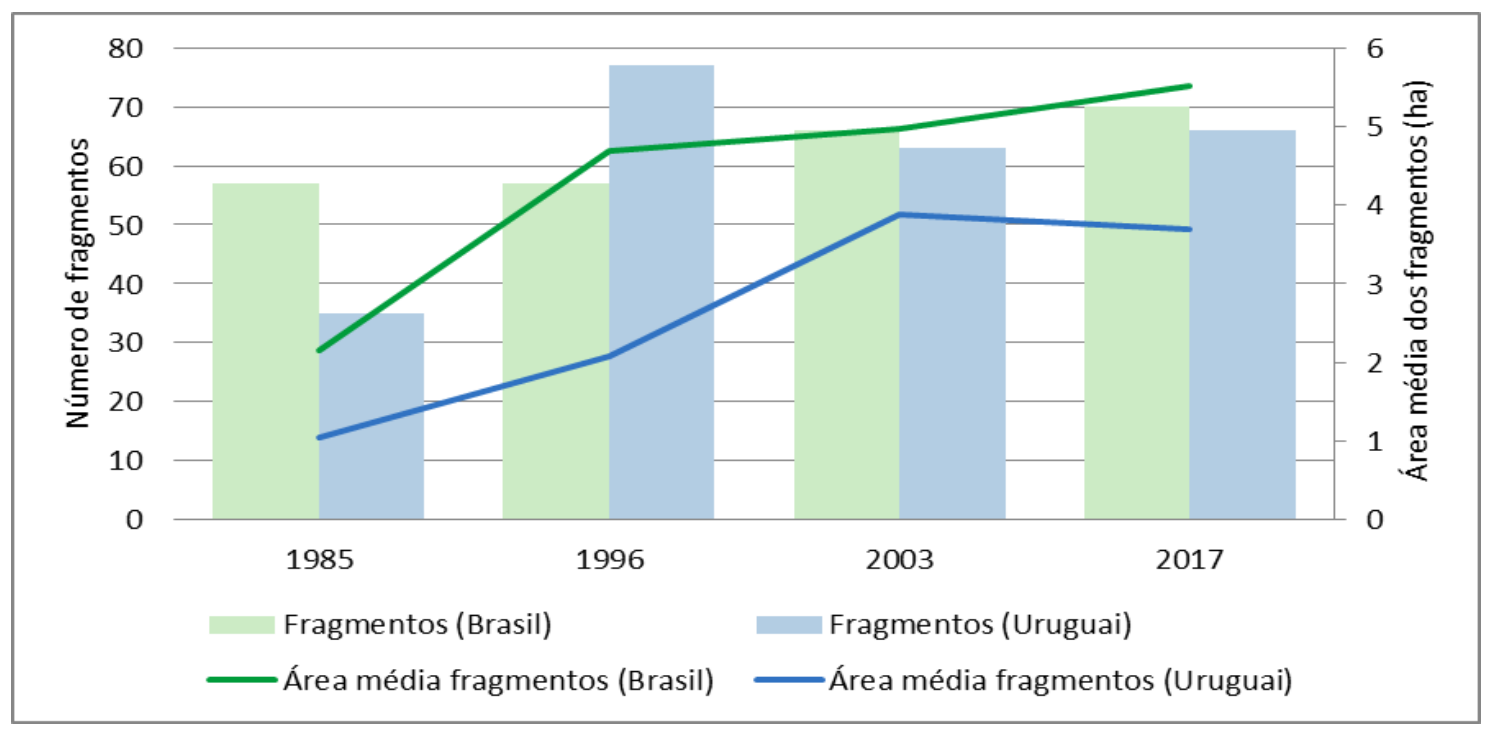

Figura 12: Número e área média de fragmentos da classe "Corpo d'água" no período em estudo. Fonte: Os autores, 2019.

Os corpos d'água apresentaram considerável aumento ao longo do período em estudo. Em 1985 ocupavam 1,34\% e 0,58\% das partes da bacia hidrográfica em territórios brasileiro e uruguaio, respectivamente. Em 2017 passaram a ocupar $3,81 \%$ (949ha) e $3,14 \%$ (766,17haA maior intensidade de aumento foi registrada no período 2003-2017 em território brasileiro (340ha) e no período 1985-1996 (303ha) em território uruguaio. ). Na figura 12, é possível verificar comportamentos distintos com relação à fragmentação dos corpos d'água nos territórios brasileiro e uruguaio.

$\mathrm{Na}$ comparação entre 1985 e 1996, as áreas ocupadas por corpos d'água aumentaram a uma taxa de 43,77 ha ano $^{-1}$, sendo a 16,15 ha $^{-1} o^{-1}$ em território brasileiro e a $27,62 \mathrm{ha} \mathrm{ano}^{-1} \mathrm{em}$ território uruguaio. Em território uruguaio, o número de fragmentos aumentou consideravelmente, acompanhado pelo aumento em sua área média. Já em território brasileiro o número de fragmentos permaneceu o mesmo, apesar do aumento em sua área média. Entre 1996 e 2003, registrou-se novo aumento, a uma taxa de 47,07ha ano $^{-1}$, com 14,16ha ano $^{-1}$ na parte brasileira e 32,91 ha ano ${ }^{-1}$ na parte uruguaia. Houve aumento no número e na área média dos fragmentos em território brasileiro. Já no Uruguai, registrou-se redução no número de fragmentos e aumento em sua área média. Entre 2003 e 2017, o aumento nas áreas ocupadas por corpos d'água se deu a taxas de $30,65 \mathrm{ha} \mathrm{ano}^{-1}$, sendo a $24,27 \mathrm{ha}$ ano${ }^{1}$ no Brasil e a 6,38ha ano ${ }^{-1}$ no Uruguai. Verificouse aumento no número de fragmentos nas duas porções da bacia hidrográfica. No entanto, enquanto no Brasil esse aumento foi acompanhado por aumento da área média dos fragmentos, no Uruguai foi acompanhado por redução.

Não foram produzidos mapas de transição e persistência da silvicultura nesse estudo porque elas apresentaram relevância (quanto a área ocupada na bacia hidrográfica) somente no cenário de 2003, quando ocuparam 4,86\% da parte brasileira da bacia (1.209ha) e 3,55\% da parte uruguaia (865ha). Entre 2003 e 2017 houve uma drástica redução nas áreas ocupadas por silvicultura, principalmente em território uruguaio, onde ocupavam apenas $24 \mathrm{ha}(0,01 \%$ da área da bacia naquele país) em 2017.

\section{Conclusões}

Este estudo investigou a dinâmica do uso e cobertura na bacia hidrográfica do Arroio São Luiz, Brasil-Uruguai, em um período de 32 anos, entre 1985 e 2017, utilizando-se técnicas de sensoriamento remoto e de sistemas de informações geográficas.

Foi possível verificar alterações contundentes nos padrões de uso e cobertura da 
terra, tanto em território brasileiro quanto em território uruguaio. Essas alterações foram ocasionadas pelas alterações nas atividades econômicas relacionadas ao setor agropecuário, em particular ao avanço do cultivo de soja em áreas anteriormente utilizadas para a pecuária bovina. Embora as alterações tenham ocorrido de maneira similar nas duas partes da bacia quando se considera apenas os cenários inicial (1985) e final (2017) - redução nas áreas campestres e florestais e aumento nas áreas agrícolas e nos corpos d'água - constatou-se que elas ocorreram em períodos e intensidades diferentes em territórios brasileiro e uruguaio.

A conversão dos campos em áreas destinadas à agricultura ocorreu com maior intensidade em território uruguaio. A fragmentação das áreas campestres aumentou ao longo do período em estudo e foi maior em território brasileiro. A área média dos fragmentos reduziu. Já a fragmentação das áreas destinadas a culturas temporárias oscilou ao longo do período em estudo, mas apresentou redução entre os cenários inicial (1985) e final (2017). A área média dos fragmentos da classe "Cultura temporária" aumentou consideravelmente, com maior intensidade em território uruguaio.

As áreas florestais ocuparam maior quantidade de área em território uruguaio e apresentaram importante redução ao longo do período em estudo. A medida que essas áreas (constituídas basicamente por matas ciliares) reduziram, o número de fragmentos também reduziu, enquanto a área média do fragmentos aumentou. No período 1996-2003 detectou-se uma expressiva conversão de áreas florestais em áreas destinadas a silvicultura, tanto em território brasileiro quanto em território uruguaio.

Os corpos d'água apresentaram maior intensidade de alteração em território uruguaio até 2003, e em território brasileiro no período 20032017. O aumento das áreas ocupadas por corpos d'água que ocorreu em território uruguaio foi marcado por aumento na fragmentação e na área média dos fragmentos. Destaca-se o expressivo aumento da fragmentação no período 1985-1996, com sensível redução no restante do período. Em território brasileiro, registrou-se aumento da fragmentação e da área média dos fragmentos ao longo de todo o período em estudo.

O presente estudo consistiu no primeiro passo no contexto da articulação da gestão dos recursos hídricos com a gestão territorial na bacia hidrográfica em busca de conhecimento acerca dos aspectos físicos da bacia hidrográfica do Arroio São Luiz. Embora os resultados sejam relevantes por permitirem identificar a dinâmica do uso e cobertura da terra no período em estudo, ainda há um longo caminho a percorrer.

Como o entendimento da interdependência hidrológica é uma realidade presente nas discussões de modelos de gestão bilateral no contexto das políticas voltadas ao compartilhamento dos recursos hídricos, acreditase que a pressão antrópica - detectada parcialmente nesse estudo - demandará ações coordenadas de gestão do uso e ocupação da terra, na perspectiva da gestão integrada dos recursos hídricos transfronteiriços da bacia hidrográfica do Arroio São Luiz. Nesse sentido, salienta-se a importância do conhecimento do meio físico e social por parte do governo brasileiro e uruguaio sobre o seu território antes da promoção de discussões bilaterais. Acredita-se que o aumento do nível de embasamento técnico advindo desse conhecimento possa levar a discussões mais proveitosas, contribuindo no processo de tomada de decisão quanto ao gerenciamento integrado na área de abrangência da bacia hidrográfica. Nesse sentido, sugere-se a criação de um grupo de trabalho capaz de promover e fomentar a cooperação técnica e o intercâmbio de informações entre órgãos gestores, técnicos e pesquisadores do Brasil e do Uruguai com foco não apenas da bacia hidrográfica do Arroio São Luiz, mas em toda a bacia hidrográfica do Rio Negro.

\section{Agradecimentos}

Os autores agradecem à FAPERGS pelo apoio financeiro obtido junto ao edital Programa Pesquisador Gaúcho (processo $n^{\circ} 141632-1$ ) e ao CNPQ pela bolsa de iniciação científica.

\section{Referências}

Agência Nacional de Águas (Brasil), 2015. Conjuntura dos recursos hídricos no Brasil: regiões hidrográficas brasileiras - Edição Especial. Brasília: ANA, 2015.

Brasil. Ministério das Relações Exteriores, 1977. O tratado de cooperação para o aproveitamento dos recursos naturais e o desenvolvimento da bacia da Lagoa Mirim. Disponível em: https://www.camara.leg.br/proposicoesWeb/fic hadetramitacao?idProposicao $=167561$. Acesso em 15/07/2019.

Brasil. Ministério das Relações Exteriores, 1992. Acordo de cooperação para o aproveitamento 
dos recursos naturais e o desenvolvimento da bacia do Rio Quaraí. Disponível em: http://www.planalto.gov.br/ccivil 03/decreto/1 990-1994/D0657.htm. Acesso em 15/07/2019.

Brasil. Água e Desenvolvimento Sustentável Recursos Hídricos Fronteiriços e Transfronteiriços do Brasil, 2013. Secretaria de Assuntos Estratégicos Presidência da República. 144p.

Cabré, M. F.; Solman, S.; Núñez, M., 2016. Regional climate change scenarios over southern South America for future climate (2080-2099) using the MM5 Model. Mean, interannual variability and uncertainties. Atmósfera. Volume 29 (1), 35-60.

Chen, Y.H.; Zhou, Y.N.; Ge, Y.; An, R.; Chen, Y., 2018. Enhancing Land Cover Mapping through Integration of Pixel-Based and ObjectBased Classifications from Remotely Sensed Imagery. Remote Sensing 10 (77).

Das, P.; Behera, M. D.; Patidar, N.; Sahoo, B.; Tripathi, P.; Behera, P. R.; Srivastava, S. K., Roy, P. S.; Thakur, P.; S P Agrawal, S. P.; Krishnamurthy, Y. V. N., 2018. Impact of LULC change on the runoff, base flow and evapotranspiration dynamics in eastern Indian river basins during 1985-2005 using variable infiltration capacity approach. Journal of Earth System Science 127:19.

Dirección Nacional de Catastro. Shapes del parcelario rural y urbano. Última actualización: 7 de octubre de 2019. Disponível em: https://catalogodatos.gub.uy/dataset?res_forma $\mathrm{t}=\mathrm{SHP} \&$ page $=1$. Acesso em 24/10/2019.

Garcia, T. S.; Ribeiro, W. C., 2016. Governança de águas transfronteiriças na bacia do Prata. $3^{\circ}$ Seminário de Relações Internacionais: Repensando interesses e desafios para a inserção internacional do Brasil no século XXI. Anais. Florianópolis.

Hasenack, H.; Weber, E., 2010. Base cartográfica vetorial contínua do Rio Grande do Sul - escala 1:50.000. Porto Alegre: UFRGS Centro de Ecologia. 1 DVD-ROM. (Série Geoprocessamento n.3).

Instituto Brasileiro de Geografia e Estatística, 2013. Manual Técnico de Uso da Terra. Rio de Janeiro.
Jiménez, A.; Vilchez, F.; González, O.; Flores, S., 2018. Analysis of the Land Use and Cover Changes in the Metropolitan Area of TepicXalisco (1973-2015) through Landsat Images. Sustainability 10, 1860-1881.

Landis, J.R.; Koch, G.G., 1977. The measurement of observer agreement for categorical data. Biometrics, v.33 (1), p. 159-174.

Luo, K.; Li, B.; Moiwo, J., 2018. Monitoring Land-Use/Land-Cover Changes at a Provincial Large Scale Using an Object-Oriented Technique and Medium-Resolution RemoteSensing Images. Remote Sensing 10 (12).

Mcgarigal, K.; Cushman, S. A.; Ene, E., 2012. Fragstats v4: Spatial Pattern Analysis Program for Categorical and Continuous Maps (Computer software program produced by the authors at the University of Massachusetts). Amherst, MA: Fragstats.

Ravanello, M. M.; Pante, A. R., 2013. Outorga de direito de uso de recursos hídricos em bacia carente de dados - Rio Negro-RS. XX Simpósio Brasileiro de Recursos Hídricos. Anais. Bento Gonçalves.

Rizzoli, P., Martone, M., Gonzalez, C., Wecklich, C., Borla Tridon, D., Bräutigam, B., Bachmann, M., Schulze, D., Fritz, T., Huber, M., Wessel, B., Krieger, G., Zink, M., Moreira, A., 2017. Generation and performance assessment of the global TanDEM-X digital elevation model. ISPRS Journal of Photogrammetry and Remote Sensing 132.

Soares, G. S., 2002. Curso de Direito Internacional Público. São Paulo: Atlas. 442 p.

Teixido, N.; Garrabou, J., 2002. Spatial pattern quantification of Antarctic benthic communities using landscape indices. Marine Ecology Progress Series 242, p. 1-18.

Wessel, B., Huber, M., Wohlfart, C., Marschalk, U., Kosmann, D., Roth, A., 2018. Accuracy Assessment of the Global TanDEM-X Digital Elevation Model with GPS Data. ISPRS Journal of Photogrammetry and Remote Sensing 139, 171-182. 